\title{
O espaço discursivo de divulgação religiosa na delimitação do estilo de totalidades antagônicas
}

\author{
Sueli Maria Ramos da SILVA \\ (Universidade de São Paulo)
}

RESUMO: Propomos considerar como e por que podemos depreender dois modos diferentes e conflitantes de presença no mundo, o estilo (éthos e antiéthos) de duas cenas enunciativas contrastantes entre si, A (Catolicismo) e B (Testemunha de Jeová), a partir de textos que materializam o espaço discursivo de divulgação religiosa.

PALAVRAS-CHAVE: Divulgação religiosa; Catolicismo; Testemunha de Jeová; éthos; antiéthos

ABSTRACT: We propose to consider how and why we can deduce two different and controversial ways of presence in the world, the style (ethos) and (antiethos) of two confronting enunciative scenes, A (Catholicism) and B (Jeovah's witneses), from texts which materialize the religious divulgation discursive space.

KEYWORDS: Religious divulgation, Catholicism, Jeovah's witneses, ethos, antiethos 


\section{INTRODUÇão}

Nosso fazer sancionador, responsável pelo recorte e delimitação de totalidades, estabeleceu, dentro do campo discursivo religioso, subconjuntos de formações discursivas que correspondem ao espaço discursivo de divulgação religiosa de duas totalidades, supostamente confrontantes: Catolicismo e Testemunha de Jeová. Tomamos, portanto, um corpus doutrinário, de ensino e instrução religiosa.

A fundamentação teórica utilizada, para que fosse possível nos adequar aos objetivos do estudo proposto, consistiu das bases teóricas da Semiótica greimasiana de linha francesa, da Análise do discurso (AD) francesa, herdada pela Semiótica por meio dos conceitos elaborados por Maingueneau (1996, 1997, 2005a, 2005b), da filosofia da linguagem, dos princípios do dialogismo bakhtiniano e das noções de heterogeneidade, estabelecidas por Authier-Revuz (1982, 1990).

Ao observar as recorrências dos mecanismos de construção do sentido dos textos, refletimos sobre a noção de discurso de divulgação religiosa que permeia o espaço discursivo das totalidades em confronto, e que é pertinente à cena enunciativa partilhada em que se propõe um fazer-crer peculiar à Palavra Revelada.

Tendo por princípio que a apreensão do sentido dos textos não é algo exterior e apriorístico ao signo, mas resultante da reunião dos dois planos compreendidos pela linguagem, o plano da expressão e o plano do conteúdo, e levando em consideração julgamentos de valor e atitudes expressos pela sociedade e concretizados nos discursos, buscar-se-á, no recorte analítico proposto, analisar semioticamente como a fé, contemplada por meio do discurso de duas instituições religiosas, propicia a construção de dois ethé, segundo duas construções do Céu e da Terra. Veremos como os percursos temáticos dos dois discursos de divulgação religiosa contemplados recebem um revestimento figurativo próprio. Esse revestimento será observado por meio de duas semióticas, verbal e visual (fotografias), de modo a se considerar a presença de dois percursos figurativos conflitantes: o percurso figurativo do falso e do verdadeiro cristão. Cada texto de divulgação religiosa (unus), visto como materialização de um gênero (catecismo e publicação de estudo bíblico), permitiu que fosse depreendido o éthos das totalidades recortadas, A (Igreja Católica) e B (Testemunha de Jeová), na medida em que cada totalidade atende às próprias restrições de uma semântica global.

\section{DISSENSÃo RELIGIOSA: ÉTHOS E ANTIÉTHOS NA DIVULGAÇÃO DA FÉ}

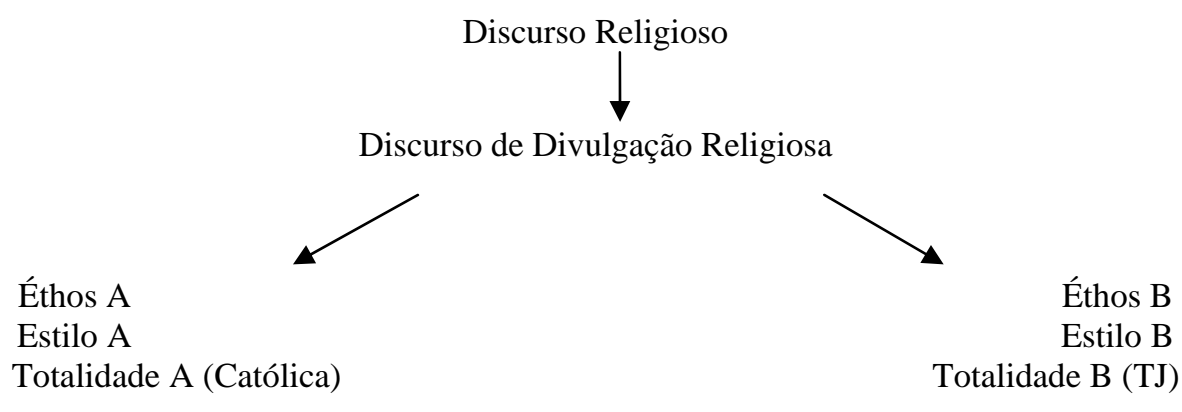


A noção de heterogeneidade é constitutiva dos discursos. Tomaremos a noção do “primado do interdiscurso” estabelecida por Maingueneau (1997, 2005a), inscrita na perspectiva bakthiniana em referência ao caráter essencialmente dialógico de todo enunciado.

Ao reconhecer o primado do interdiscurso, compreenderemos o espaço discursivo como uma rede de interações semânticas que circunscreve a especificidade de um discurso, ao estabelecer as relações desse discurso com seu "Outro”.

Desse modo, ao termos procedido ao recorte de duas totalidades antagônicas, teremos, portanto, o embate entre duas interincompreensões, o que resulta em duas profissões de fé que se opõem entre si.

A assimilação de simulacros das imagens ditadas pela crença se refere aos diferentes modos de pensar o mundo, relacionados aos interesses de grupos sociais postos em confronto e ligados à instituição religiosa que os legitima.

A formação ideológica dos discursos de divulgação religiosa é constituída por um éthos mediador, de tom de voz próprio daquele que ensina, orienta e dita ao leitor aprendiz (páthos) determinadas regras de conduta de como pensar e proceder por meio de formações discursivas. As formações discursivas agrupam ao longo dos textos de divulgação religiosa temas que refletem diferentes categorizações de mundo, que se materializam através de figuras, em consonância com as restrições de cada totalidade discursiva.

Tomemos como base exemplos de temas e figuras extraídos do enunciado verbal da brochura de estudo bíblico e que remetem à construções contraditórias de mundo, de modo a se configurar em uma totalidade (TJ) a negação de seu contrário (Catolicismo). O enunciador das TJ pauta seu discurso pela negação dos seguintes temas pertencentes ao discurso católico no enunciado instrucional considerado: a) necessidade de celebração da solenidade da santíssima trindade: a) trindade de Deus; b) necessidade de celebração do natal e da páscoa; c) necessidade de celebração de aniversários natalícios; d) reverência aos mortos: (Finados); e) a reverência à cruz com seu poder simbólico: exaltação da santa cruz.

a) Necessidade de celebração da solenidade da santíssima trindade: a trindade de Deus:

Trindade: É Jeová uma Trindade — três pessoas em um só Deus? Não! Jeová, o Pai, é “o único Deus verdadeiro” (O QUE DEUS requer de nós, 1996:22).

b) Necessidade de celebração do natal e da páscoa:

O Natal e seus costumes originaram-se de antigas religiões falsas. O mesmo se dá com os costumes atuais da chamada Páscoa, tais como o uso de ovos e de coelhos. Os primeiros cristãos não celebravam nem o Natal, nem a Páscoa moderna, tampouco o fazem hoje em dia os verdadeiros cristãos (Ibidem).

c) Necessidade de celebração de aniversários natalícios:

O costume de celebrar natalícios originou-se das antigas religiões falsas. Os cristãos verdadeiros dão presentes e se divertem juntos em outras ocasiões do ano (Idem, 1996:23). 
d) Reverência aos mortos: (Finados):

Os costumes que têm que ver com o medo ou a adoração dos mortos são errados (Ibidem).

e) A reverência à cruz com seu poder simbólico: exaltação da santa cruz:

O símbolo da cruz vem de antigas religiões falsas. Os primeiros cristãos não usavam nem adoravam a cruz. Portanto, você acha certo usar uma cruz na adoração? (Ibidem).

Vejamos como o discurso do catecismo católico tematiza e figurativiza as verdades contraditórias às propugnadas pelas TJ. Examinaremos o discurso do Compêndio do Catecismo da Igreja Católica.

a) Necessidade de celebração da solenidade da santíssima trindade: a trindade de Deus:

\section{Como a Igreja exprime a sua fé trinitária?}

A Igreja exprime a sua fé trinitária ao confessar um só Deus em três Pessoas: Pai, Filho e Espírito Santo. As três Pessoas divinas são um só Deus porque cada uma delas é idêntica à plenitude da única e indivisível natureza divina. Elas são realmente distintas entre si pelas relações que as põe em referência umas com as outras: o Pai gera o Filho, o Filho é gerado pelo Pai, o Espírito Santo procede do Pai e do Filho (Bento XVI, 2005:36)

b) Necessidade de celebração do natal e da páscoa:

103. O que ensina o Evangelho sobre os Mistérios do nascimento e da infância de Jesus?

No Natal, a glória do Céu se manifesta na fraqueza de uma criança; a circuncisão de Jesus é sinal e sua inserção no povo hebraico e prefiguração do nosso Batismo; a Epifania é a manifestação do Rei-Messias de Israel a todas as nações, na sua apresentação no templo, em Simeão e Ana é toda a espera de Israel que vem ao encontro do seu Salvador; a fuga para o Egito e a matança dos inocentes anunciam que toda a vida de Cristo estará sob o sinal da perseguição; a sua volta do Egito lembra o Êxodo e apresenta Jesus como o novo Moisés; ele é o verdadeiro e definitivo libertador (Bento XVI, 2005:48).

241. Qual é o centro do tempo litúrgico?

O centro do tempo litúrgico é o domingo, fundamento e núcleo de todo o ano litúrgico, que tem o seu ápice na Páscoa anual, a festa das festas (Idem, 2005:84).

c) Reverência aos mortos: (Finados):

\section{O que exprimem os funerais?}

Os funerais, embora celebrados segundo diferentes ritos correspondentes às situações e às tradições de cada região, exprimem o caráter pascal da morte cristã na esperança da ressurreição, e o sentido da comunhão com o defunto particularmente mediante a oração e a purificação da sua alma (Idem, 2005:110-111). 
d) Reverência à cruz com seu poder simbólico: exaltação da santa cruz:

280. Em que sentido a Eucaristia é memorial do sacrifício de Cristo?

A Eucaristia é memorial no sentido de que torna presente e atual o sacrifício que Cristo ofereceu ao Pai na cruz, uma vez por todas, em favor da humanidade. O caráter sacrificial da Eucaristia se manifesta nas próprias palavras da instituição: "Isto é o meu corpo que é dado por vós” e "Este cálice é a nova aliança no meu sangue, que é derramado por vós” (Lc 22, 19-20). O sacrifício da cruz e o sacrifício da Eucaristia são um único sacrifício. Idênticos são a vítima e o oferente, diferente é apenas o modo de oferecer: cruento na cruz, incruento na Eucaristia (Idem, 2005:94).

Vejamos como esses percursos temáticos do discurso católico de divulgação religiosa, refutados pelo sistema de valores das TJ, recebem um revestimento figurativo próprio, concretizado por meio de duas semióticas, verbal e visual (fotografias), de modo a se considerar a presença de dois percursos figurativos conflitantes: o percurso figurativo do falso e do verdadeiro cristão.

\subsection{DISCURSO (TJ.) DE DIVULGAÇÃO RELIGIOSA PERCURSOS Figurativos}

\section{O Verdadeiro Cristão}

- Jeová, o pai como “o único Deus verdadeiro”. O pai é maior do que o filho. O Espírito Santo como força ativa de Deus;

- Marco referencial natalício: $1^{0}$. de outubro;

- Ausência de celebração da Páscoa e Natal;

- Ausência de celebração de aniversários natalícios;

- Ausência de exaltação da santa Cruz - A alma morre, não continua viva após a morte.

\section{O Falso Cristão}

- Trindade: Pai equivalente ao Filho e ao Espírito Santo;

- Marco referencial natalício: 25 de dezembro;

- Símbolos pascais: ovos de Páscoa, Coelhos;

- Aniversários natalícios;

- Adoração do símbolo da cruz;

- A vida é um dom de Deus e a morte não a pode sufocar.

A análise dos mecanismos de tematização e figurativização demonstra ainda que a negação de seu contrário está contida no próprio texto. Os temas e figuras católicos, reportados no enunciado instrucional da brochura $O$ que Deus Requer de Nós, são negados, atravessados pela exclusão. O catolicismo é dado como o discurso renegado, de tal modo que se demonstra, através da argumentação verbal, a não convergência entre os dogmas católicos e o enunciado adversário. Para legitimar o caráter de autoridade do texto considerado, invoca-se continuamente a autoridade da Sagrada Escritura. Entretanto, a citação da autoridade da Sagrada Escritura só é aceitável no círculo do mesmo, devido à submissão ao sistema de restrições de sua própria formação discursiva. Para não se colocar em contradição, o enunciado opera com o 
estabelecimento de uma triagem de citações, a fim de convocar apenas os fragmentos da Bíblia que estariam de acordo com o sentido do sistema de restrições do enunciador da brochura instrucional.

1. Nem todas as crenças e costumes são maus. Mas Deus não os aprova quando se originam de religião falsa ou são contrários a outros ensinos bíblicos. — Mateus 15:6.

2. Trindade: É Jeová uma Trindade — três pessoas em um só Deus? Não! Jeová, o Pai, é “o único Deus verdadeiro”. (João 17:3; Marcos 12:29) Jesus é Seu Filho primogênito e está sujeito a Deus. (1 Coríntios 11:3) O Pai é maior do que o Filho. (João 14:28) O espírito santo não é pessoa; é a força ativa de Deus. — Gênesis 1:2; Atos 2:18.

3. Natal e Páscoa: Jesus não nasceu em 25 de dezembro. Ele nasceu por volta de $1 .^{\circ}$ de outubro, época do ano em que os pastores mantinham seus rebanhos ao ar livre, à noite. (Lucas 2:8-12) Jesus nunca ordenou que os cristãos celebrassem seu nascimento. Antes, mandou que comemorassem ou recordassem sua morte. (Lucas 22:19, 20) O Natal e seus costumes originaram-se de antigas religiões falsas. O mesmo se dá com os costumes atuais da chamada Páscoa, tais como o uso de ovos e de coelhos. Os primeiros cristãos não celebravam nem o Natal, nem a Páscoa moderna, tampouco o fazem hoje em dia os verdadeiros cristãos.

4. Aniversários natalícios: Os únicos dois aniversários natalícios mencionados na Bíblia eram de pessoas que não adoravam a Jeová. (Gênesis 40:20-22; Marcos 6:21, 22, 2427) Os primeiros cristãos não celebravam aniversários natalícios. O costume de celebrar natalícios originou-se das antigas religiões falsas. Os cristãos verdadeiros dão presentes e se divertem juntos em outras ocasiões do ano.

5. Medo dos mortos: Os mortos não podem fazer nem sentir nada. Não podemos ajudálos, nem podem eles prejudicar-nos. (Salmo 146:4; Eclesiastes 9:5, 10) A alma morre; não continua viva após a morte. (Ezequiel 18:4) Mas às vezes anjos iníquos, chamados demônios, fingem ser espíritos de mortos. Os costumes que têm que ver com o medo ou a adoração dos mortos são errados. - Isaías 8:19.

6. A cruz: Jesus não morreu numa cruz. Ele morreu num poste, ou estaca. A palavra grega, em muitas Bíblias traduzida “cruz”, refere-se apenas a um madeiro. O símbolo da cruz vem de antigas religiões falsas. Os primeiros cristãos não usavam nem adoravam a cruz. Portanto, você acha certo usar uma cruz na adoração? Deuteronômio 7:26; 1 Coríntios 10:14.

7. Pode ser muito difícil abandonar algumas dessas crenças e costumes. Parentes e amigos talvez procurem convencê-lo a não mudar de crença. No entanto, agradar a Deus é mais importante do que agradar a homens. - Provérbios 29:25; Mateus 10:36, 37.

(O QUE DEUS requer de nós, 1996:22-23) [grifo nosso]

A citação dos temas do Outro (Catolicismo) apresenta um papel crucial, pois, pela utilização da referência bíblica, afirma-se no enunciado a inexatidão das informações do discurso adversário. O modo de polemizar do enunciador da brochura se dá pela instauração do seu “Outro", considerado desqualificado, pois este “Outro" 
fornece informações incongruentes com os ensinamentos bíblicos, dentro da visão da formação ideológica das TJ.

O visual sincretizado ao verbal, no gênero compêndio didático de estudo bíblico da TJ, é discursivizado como expansão das figuras verbais, apresentando, portanto, o icônico em uma relação de completude com o verbal, o que viabiliza a leitura linear e facilitada, própria ao tom professoral, que permeia a brochura de estudo bíblico.

Ilustração 1 - Deus não é uma trindade (Anexo 1).

Ilustração 2 - O Natal e a Páscoa moderna vêm de antigas religiões falsas (Anexo 2).

Ilustração 3 - Não há nenhum motivo para adorar os mortos ou ter medo deles (Anexo 3).

As fotografias que aludem aos temas do discurso católico (a trindade de Deus, a necessidade de celebração do Natal e da páscoa, a reverência aos mortos e a reverência à cruz com seu poder simbólico) ganham um novo sentido quando verificamos que os temas e figuras contemplados remetem a construções contraditórias de mundo, de modo a se configurar em uma totalidade (Testemunha de Jeová) a negação de seu contrário (Catolicismo).

A ilustração 3 também figurativiza a presença da umbanda, doutrina espiritualista originária do pensamento africano, pois esta partilha de valores éticos cristãos, que são refutados pelo enunciado instrucional. Entre os valores refutados, o enunciado visual figurativiza a adoração da cruz e reverência aos mortos, expressos no culto ritualístico dos antepassados. A umbanda apresenta explícita referência às crenças católicas: "Nos ritos da umbanda, as preces católicas e a invocação de Jesus, Maria e dos santos da igreja nas letras dos cantos sagrados continuam indispensáveis” (Prandi, 2004:228).

A presença do enunciado visual, ao concretizar e reforçar o repudiável, de acordo com a orientação argumentativa do discurso das TJ, instaura de maneira visível e palpável aos olhos do enunciatário, um culto tido como "errado" a esse sistema de valores.

Ao tomar como base as legendas que acompanham as fotografias da lição, observamos que a ancoragem se dá em nível polêmico. As relações estabelecidas, no que concerne à homologia entre o verbal e o visual, estabelecem no plano do conteúdo a figura central e emblemática do verdadeiro cristão, dada por meio das modalidades veridictórias. A imagem traçada para o enunciatário é a daquele que parece e é cristão. Assim, temos o verdadeiro (Testemunha de Jeová) e o falso (o outro) não nomeado.

A observação dos procedimentos de tematização e figurativização, inerentes à brochura de estudo bíblico, permitiu tecer algumas observações concernentes à "interincompreensão constitutiva", para a qual podemos postular a interseção entre os dois discursos: Católico e TJ. A incorporação dos percursos temáticos e figurativos do discurso católico desenvolve-se mediante a utilização do procedimento interdiscursivo de citação em nível polêmico.

Esse processo de duplas traduções permite-nos aprofundar o mecanismo polêmico. Cada uma das formações discursivas do espaço discursivo só pode traduzir como "negativas", inaceitáveis, as unidades de sentido construídas por seu Outro, pois é 


\begin{abstract}
através desta rejeição que cada uma define a sua identidade. Uma formação discursiva opõe dois conjuntos de categorias semânticas, as reivindicadas (chamemo-las de "positivas”) e as recusadas (as "negativas"). Note-se que ela projeta as unidades "positivas" deste Outro sobre as categorias de seu próprio sistema; para preservar sua identidade, o discurso só pode relacionar-se com o Outro do espaço discursivo através do simulacro que dele constrói. Chamaremos de discurso agente aquele que se encontra em posição de "tradutor", de construtor de simulacro, e de discurso paciente aquele que desta forma é traduzido (Maingueneau, 1997:122).
\end{abstract}

Ao considerar o sistema de restrições semânticas que organiza cada uma das totalidades consideradas, verificamos a presença do tom polêmico, da negação do universo semântico do outro, da pejoração do outro como simulacro, na medida em que essa "interincompreensão" repousa sob dois conjuntos de semas: os positivos reivindicados e os negativos rejeitados. Desse modo, o "Outro" (o Catolicismo) é traduzido nas categorias do registro negativo dentro do sistema das TJ. O modo próprio de polemizar dá-se pela colocação do outro em erro. O "Outro" (Catolicismo), ao apresentar como positivos os semas rejeitados pela totalidade discursiva das TJ, é desqualificado enquanto adversário.

O éthos da TJ. constrói a intersubjetividade dada polemicamente por meio do embate entre duas inter(in)compreensões de mundo, que supõe duas compreensões da fé em Deus e que consolida a inter(in)compreensão constitutiva de cada discurso.

\title{
3. ConClusão
}

O embate entre duas interincompreensões nos permite postular a existência de um éthos e de um antiéthos inerente à divulgação da fé. Descrever o éthos das totalidades discursivas postas em confronto permite recuperar o caráter, o tom de voz, o corpo e o estilo de sujeitos determinados pelo modo de dizer e viabilizados pela identificação de temas e figuras ressemantizados pelos próprios discursos.

A esse éthos, que ressurge a polêmica em seu próprio discurso, se opõe o éthos católico pautado pelo efeito de monofonia.

O catolicismo confirma o antiéthos da TJ, que ao silenciar a polêmica, confirma um acento único de voz, um efeito de monofonia. Embora ambas as totalidades configurem-se como discursos autoritários, de verdade única e de voz altiva, o discurso católico, ao abafar as vozes em conflito, confirma-se como um discurso monofônico, de voz "marmórea”, inquestionável e respaldada pelos valores da tradição católica.

O éthos da TJ, de modo contrário, só se constitui por oposição ao outro (catolicismo), pelo embate de duas posições determinadas pelo ressurgimento da polêmica.

Desse modo, delineamos, em consonância a cada totalidade A (Católica) e B (TJ), um éthos que operacionaliza a depreensão de dois estilos, de duas profissões de fé, que são determinadas por meio dos diferentes modos de discursivização de temas e figuras. 


\section{REFERÊNCIAS BIBLIOGRÁFICAS}

AUTHIER-REVUZ. J. "Hetérogénéité montée et hétérogénéité constitutive: élements pour une aprouche de l'autre dans le discours.” In: DRLAV: Paris: Centre de Recherches de l’Université de Paris, Revue de Linguistique, VIIi, 26, 1982, p. 91151.

BENTO XVI. Compêndio do catecismo da Igreja católica. São Paulo: Loyola, 2005.

DISCINI, Norma. O estilo nos textos. São Paulo: Contexto, 2004b.

MAINGUENEAU, Dominique. A gênese dos discursos. Curitiba: Criar Edições, 2005a.

O QUE DEUS requer de nós. São Paulo: Sociedade Torre de Vigia de Bíblias e Tratados, 1996.

PRANDI, Reginaldo. O Brasil com axé: candomblé e umbanda no mercado religioso. In: JACOB, César Romero et al. Dossiê religiões no Brasil. São Paulo: IEA, vol. 18, no. 52, de setembro a dezembro de 2004, p. 223-238.

\section{Anexo}

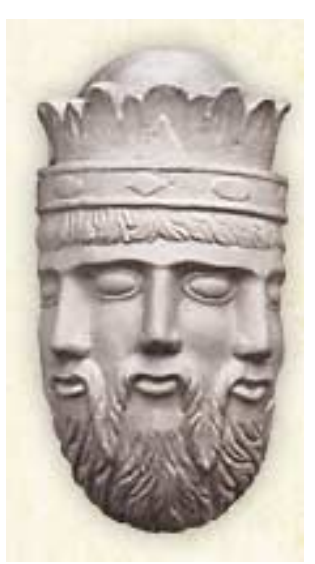

\section{Ilustração 1}

Deus não é uma trindade.

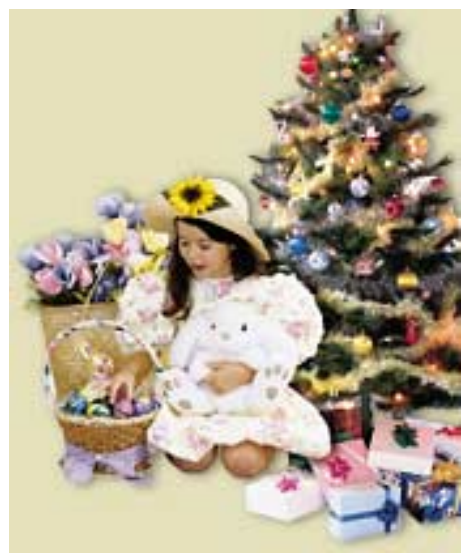

Ilustração 2

O Natal e a Páscoa moderna vêm de antigas religiões falsas. 


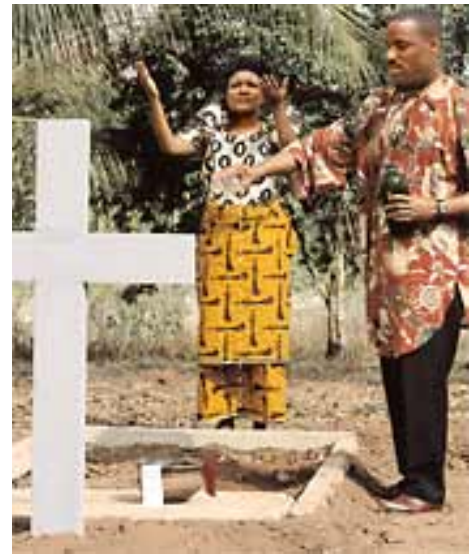

\section{Ilustração 3}

Não há nenhum motivo para adorar os mortos ou ter medo deles.

\section{Como citar este artigo:}

SILVA, Sueli Maria Ramos da. O espaço discursivo de divulgação religiosa na delimitação do estilo de totalidades antagônicas. Estudos Semióticos. [online] Disponível na Internet via WWW.URL: http://www.fflch.usp.br/dl/semiotica/es. Editor Peter Dietrich. Número 4, São Paulo, 2008. Acesso em "dia/mês/ano". 